\title{
ERRATUM
}

\author{
Mark W. Renner · Jack Fajer
}

\section{Oxidative chemistry of nickel porphyrins}

Published online: 20 December 2001

(C) SBIC 2001

\section{J Biol Inorg Chem (2001) 6:823-830}

In both the online and the printed version of this article an entire sentence is missing on p. 827 in the last paragraph of the Literature survey. The correct paragraph is below:

At $110 \mathrm{~K}, \mathrm{Ni}(\mathrm{III}) \mathrm{OEP}(\mathrm{CN})_{2}^{-}$displays an EPR spectrum consistent with a tetragonally compressed geometry and $d_{\mathrm{x}^{2}-\mathrm{y}^{2}}$ occupancy: $\mathrm{g}_{\perp}=2.053$ and $\mathrm{g}_{\|}=2.167$ with well-resolved hyperfine couplings to the four pyrrole nitrogens (nine lines): $A_{N_{\perp}}=14.0 \mathrm{G}$, $\mathrm{A}_{\mathrm{N}||}=11.8 \mathrm{G}$. The hyperfine couplings to the four nitrogens are even observed at room temperature. $\mathrm{Ni}(\mathrm{III}) \mathrm{T}(n \mathrm{Pr}) \mathrm{P}(\mathrm{CN})_{2}^{-}$exhibits a similar EPR spectrum with well-resolved hyperfine from the four porphyrin nitrogens: $\mathrm{g}_{\perp}=2.053 \quad\left(\mathrm{~A}_{\mathrm{N}}=14.3 \mathrm{G}\right)$ and $\mathrm{g}_{||}=2.165$ $\left(A_{N}=12.0 \mathrm{G}\right)$. Since OEPs and tetraalkylporphyrins have different HOMOs, $\mathrm{a}_{1 \mathrm{u}}$ and $\mathrm{a}_{2 \mathrm{u}}$, respectively [33], these clearly do not affect the $\mathrm{Ni}(\mathrm{III})$ species with a tetragonally compressed $\left(d_{\mathrm{x}^{2}-\mathrm{y}^{2}}\right)^{1}$ configuration. In contrast to the results for $\mathrm{Ni}(\mathrm{III}) \mathrm{TPP}(\mathrm{CN})_{2}^{-}$[25],
$\mathrm{Ni}(\mathrm{III}) \mathrm{OEP}(\mathrm{CN})_{2}^{-}$, and $\mathrm{Ni}(\mathrm{III}) \mathrm{T}(n \mathrm{Pr}) \mathrm{P}(\mathrm{CN})_{2}^{-}$, which unambiguously show $d_{\mathrm{x}^{2}-\mathrm{y}^{2}}$ occupancy, oxidation of $\mathrm{Ni}(t-\mathrm{Bu}) \mathrm{P}$ in the presence of cyanide yields an EPR spectrum with $\mathrm{g}_{\perp}=2.12$ and $\mathrm{g}_{\mid}=2.017$ without any pyrrole nitrogen hyperfine, i.e., a $d_{\mathrm{z}^{2}}$ occupancy. This assignment is further confirmed with ${ }^{13} \mathrm{CN}^{-}(\mathrm{I}=1 / 2$ instead of $\mathrm{I}=0$ for ${ }^{12} \mathrm{C}$ ): each EPR peak is split into triplets due to the two axial ${ }^{13} \mathrm{CN}^{-}$with $\mathrm{A}_{{ }_{13} \mathrm{C}}=71$ and $80 \mathrm{G}$ for $\mathrm{g}_{\perp}$ and $\mathrm{g}_{\|}$, respectively. (The large ${ }^{13} \mathrm{C}$ hyperfine couplings are consistent with those observed in the much simpler $\left[\mathrm{Ni}(\mathrm{III})\left({ }^{13} \mathrm{CN}\right)_{6}\right]^{-3}$ in which the unpaired electron is also in the $d_{\mathrm{Z}^{2}}$ orbital at $80 \mathrm{~K}$ : $A_{\perp}=92 \mathrm{G}$ and $A_{\|}=100 \mathrm{G}$ [43]. $\}$ We ascribe the unusual behavior of $\mathrm{Ni}(t-\mathrm{Bu}) \mathrm{P}$ to the fact that it is so sterically constrained by the bulky $t$-butyl meso substituents [36] that its core cannot readily expand to accommodate the long Ni-N distances required by a $d_{\mathrm{x}^{2}-\mathrm{y}^{2}}$ orbital occupancy (see the discussion below).
The online version of the original article can be found at http:// dx.doi.org/10.1007/s007750100276

M.W. Renner · J. Fajer $(\bowtie)$

Energy Sciences and Technology Department, Brookhaven National Laboratory, Upton, NY 11974-5000, USA

E-mail: fajerj@bnl.gov

Tel.: + 1-631-344-4521

Fax: + 1-631-344-5815 